\title{
Significado de una educación multicultural en la sociedad de hoy
}

\author{
Mariapia LAMBERTI \\ Universidad Nacional Autónoma de México
}

La presente conferencia fue pronunciada en el coloquio "Pluralidad de LenguasCulturas", dos jornadas consagradas a la reflexión sobre la importancia de la enseñanza y el aprendizaje de diferentes lenguas y de sus implicaciones culturales. El estudio de las lenguas que existen - y también de aquellas que han muerto- nos permite entrar en el camino de la alteridad y de la diversidad, e incluso enriquecer nuestra visión del mundo puesto que también su configuración lingüística es el reflejo de una manera de pensar y de un contexto cultural determinado. Es momento de celebrar la pluralidad y de comprender que el interés cultural por la diversidad de lenguas es, al final, lo que prologa su existencia.

PALABRAS ClAVE: Babel, enseñanza, aprendizaje, lenguas, culturas, pluralidad, supervivencia.

This lecture was presented in the colloquium "Plurality of Languages-Cultures", a two day discussion panel dedicated to talk about the importance of teaching and learning different languages and their cultural implications. The study of existing languages — and also of those that aren't anymore - allows us to enter the path of otherness and diversity, and even enrich our worldview because the linguistic configuration of a language is the reflection of a population's viewpoint and cultural context. It's time to celebrate plurality and to understand that the cultural interest in language diversity is, in the end, what extends their existence.

KEY WORDS: Babel, teaching, learning, languages, cultures, plurality, survival.

El cartel que hemos escogido para anunciar estas Jornadas representa la torre de Babel. El relato bíblico que ha inspirado a innumerables artistas en el transcurso de los siglos, y nos ha inspirado hoy, presenta a propósito de esta torre una historia que todos conocemos: un castigo de Dios por la soberbia del hombre.

Y sí, la enorme variedad de lenguas que caracteriza a la humanidad, sus sucesivos nacimientos y muertes, la dificultad — cuando no imposibilidad — de comunicación entre seres humanos debida a la multiplicidad de lenguas, ha sido percibida como un obstáculo, o, como en el caso del relato de Babel, como una maldición.

Hay otro elemento en el transcurso milenario de la multiplicidad lingüística que destaca inmediatamente. La humanidad ha creado —o, si se prefiere, buscado — lenguas 
que podemos definir 'perfectas', que sirvieran de intercomunicación: nos viene a la mente inmediatamente el griego, para el pensamiento profundo, lengua con extraordinarias posibilidades de conjuntar palabras-conceptos para formar nuevos conceptospalabras; el latín con su precisión sintáctica insuperable, lengua incontrovertible en las definiciones legales; y el sánscrito con su fonética exhaustiva de todos los posibles sonidos emitidos por el aparato fonatorio humano, lengua, se puede decir, creada específicamente con parámetros de precisión absoluta para hablar de y con los dioses.

Pero estas tres lenguas fueron - y en el caso del sánscrito se puede decir que todavía es - también lenguas habladas, pertenecientes a pueblos y civilizaciones con una historia propia, que determinó en su momento su permanencia, su difusión o su declino.

Sin Salamina, Maratón, Platea; sin las Termópilas, sin el heroísmo suicida de Leónidas y la inteligente estrategia de Temístocles y Pausania, pero sobre todo sin la loca y triunfal aventura de Alejandro de Macedonia, hoy la lengua de las ciencias y de la medicina no sería la que es, con sus términos griegos y su posibilidad de combinaciones; y probablemente, ni siquiera el mundo de la ciencia habría progresado lo que hoy constatamos, sin aquella claridad conceptual y definitoria.

La lengua latina se impuso en toda la cuenca del Mediterráneo gracias a las armas y la sabia política de Roma, que disfrazaba de alianza lo que en realidad era una subyugación, recurriendo a la guerra de castigo y al genocidio sólo cuando algunos pueblos decidían seguir su propio camino sustrayéndose a los intereses económico-políticos de la Ciudad por antonomasia.

La lengua impuesta por los conquistadores era una lengua perfecta. La lógica sintáctica, la precisión expresiva del latín no tenían ni tuvieron igual. Sin embargo, el latín no se impuso en Grecia y en las zonas helenizadas: Graecia capta ferum victorem cepit, et artes/ intulit agresti Latio, como sintetizó Horacio (Epistolae, II, 1, Ad Augustum, vv. 156-157); la fuerza de la cultura greca impidió la desaparición de la lengua de Sócrates, y ésta se impuso a lado del latín sincretizando la cultura griega con la cultura del feroz conquistador, con buena paz de Marco Porcio Catón conocido como el Censor, que veía en esta simbiosis el germen de la decadencia romana.

Pero la lengua latina también tuvo que morir: y su muerte consistió no en la desaparición, sino en una serie de transformaciones debidas al fin de su poderío militar y al contacto con las múltiples lenguas de los antiguos aliados, que impusieron su renovada potencia sobre el antiguo dominador; o las lenguas de pueblos invasores que arrasaron sin misericordia los territorios antes romanos.

Maldición divina, ley del más fuerte; y a esto podemos agregar la ley natural universal insoslayable, que dicta que todo ser vivo evoluciona cambia y muere.

¿Qué significado tienen al día de hoy estos tres principios? ¿Tenemos que aceptarlos como fatalidad ineludible?

Para hablar de la multiplicidad lingüística en nuestros tiempos presentes, creo indispensable detenernos un momento sobre el significado de un término-concepto controversial en nuestros años, et término globalización. 
Sin detenernos sobre las vertientes económicas neoliberalistas que son las que determinan mayor crítica y temor, mayor controversia y hostilidad, podemos ver la globalización como un fenómeno imparable de unificación cultural, que depende sobre todo del desarrollo extraordinario que la tecnología de la comunicación ha tenido en el último medio siglo. No sólo la ropa que usamos y lo que comemos se ha uniformado en gran parte del mundo, sino también las casas que habitamos, los medios de transporte, los aparatos domésticos se han vuelto básicamente los mismos; pero sobre todo es la misma la civilización visual y comunicativa en las que nos hemos sumergido, la que nos permite tener contacto diariamente con lugares que no conocemos, con personas de latitudes diferentes, con usos y costumbres que a menudo pueden contradecir los nuestros, o enseñarnos algo; es la tecnología que nos permite asistir presencialmente a episodios trágicos o sorprendentes o estimulantes, que despiertan interés, curiosidad, pero que también a menudo representan una perspectiva para tener oportunidades diferentes en la vida. Si todavía existe - y lo sabemos - la trágica condición de quien emigra sólo para encontrar una situación económica básica que su país natal no le ofrece, hoy es común una emigración por intereses personales, por deseo de cambio; o también para perseguir un ideal humanitario: pensemos en los médicos sin fronteras, por ejemplo.

La necesidad de aprender idiomas ya no se percibe como una maldición divina, sino como un estímulo entusiasmante a acercarnos y conocernos más entre hombres y pueblos.

Aprender un idioma —o más de uno - se ha vuelto indispensable, pero sobre todo se ha vuelto el medio príncipe para abrir una ventana al mundo. La enseñanza de una lengua extranjera es, debe de ser hoy, elemento básico de la educación escolar.

Pues hay otro elemento que se ha 'globalizado', o si preferimos, difundido ampliamente en el mundo: la capacidad de lecto-escritura, el conocimiento de nociones básicas, se considera hoy en la mayor parte del mundo no un privilegio, sino un derecho humano fundamental. Por poner sólo un ejemplo, en este país el analfabetismo que a principio del siglo XX era casi del $90 \%$, a finales del mismo siglo era de cerca del $9 \%$, y en vía de desaparición.

Y aquí se presenta el gran reto de nuestros tiempos. ¿Qué rol está teniendo la enseñanza de idiomas en el sistema escolar globalizado de hoy?

La prioridad indispensable de la enseñanza de idiomas ha provocado un desarrollo extraordinario de los estudios lingüísticos y didácticos. Si la filología lingüística ha existido desde siempre, se puede decir, desde el gramático Pānini con sus tres mil novecientas cincuenta y nueve reglas morfológicas del sánscrito - y algunos estudiosos opinan que esto sucedió en época en que la escritura todavía no se usaba en la India-, que la didáctica se ha presentado como ciencia en sí sólo en tiempos muy recientes, suplantando en muchos ámbitos la pedagogía, que había sido tradicionalmente una rama de la filosofía, y sólo a principio del siglo XX se había imbricado con la psicología.

Si la filología antigua tenía como objetivo la fijación precisa y por ende la preservación de la lengua, la lingüística actual se propone estudiar la —o las — lengua como 
un fenómeno biológico, describiendo sus avatares diacrónicos, pero sobre todo su esencia profunda, descubriendo, se puede decir, su DNA. Saussure, el padre de la lingüística moderna, era profesor de sánscrito, y no escondió la influencia que Pānini tuvo sobre algunos planteamientos de sus teorías; lo estudió también Chomsky: "Judged in terms of the power, range, novelty and influence of his thought, Noam Chomsky is arguably the most important intellectual alive today", como lo definió el New York Times en 1979; pero la definición sigue válida a distancia de más de treinta años. Chomsky llegó a formular la hipótesis de una dinámica creativa del lenguaje en todos los seres humanos, una gramática generativa universal, que deriva de la capacidad biológica del homo sapiens, único entre todas las especies animales en poseer este funcionamiento cerebral. El hecho de que todos los seres humanos posean esta capacidad innata de comunicación articulada, implicaría la existencia de elementos universales en la estructuración del lenguaje, así como nos es común a todos el funcionamiento de los órganos vitales de nuestro cuerpo. Como tal, tiene sus leyes inmutables, su modo de funcionar inalterable.

Además, el principio chomskiano aceptado como base de la lingüística moderna es que las formaciones posibles a partir de estas estructuras básicas - relacionales, fonéticas y semánticas - son infinitas e irrepetibles, como, para hacer un símil, las huellas digitales. El número de frases que podemos crear y hemos creado son infinitas. La gramática entonces tiene una finalidad descriptiva, no una finalidad normativa. La evolución y muerte de las lenguas se entiende como un fenómeno biológico imparable. Las lenguas se contaminan y pierden sus características iniciales por contacto con otras, a causa de conquistas o subyugación de un pueblo por otro; o por preeminencia de otras lenguas en otros ámbitos; o por la necesidad de definir en forma nueva elementos nuevos de la vida cotidiana. Esta evolución es imparable como el envejecimiento celular.

Si ya hemos descartado la visión de la multiplicidad lingüística como una maldición y un castigo, ¿la ley natural es entonces aquella a la que tenemos que resignarnos? ¿O la ley del más fuerte?

Regresemos un momento a lo que pasó con el griego y el latín, para no hablar del sánscrito cuyo estudio tanto influyó sobre Saussure y el mismo Chomsky. Todos sabemos que el latín que hablamos en este momento es una derivación corrompida del que hablaba Cicerón. Y dicha corrupción, nos indican los libros de historia, se debió a las sucesivas y violentas invasiones de pueblos, que los romanos, como antes los griegos, llamaban bárbaros: una palabra que se había formado en Grecia de $\beta \alpha \rho-\beta \alpha \rho$, un sonido de burla como nuestro bla-bla, que usaban los griegos para denostar a los que no hablaban su lengua, su lengua perfecta. Pueblos salvajes en comparación con los latinos, pueblos a los que se les definía a partir de su lengua. La mezcla de sus lenguas $\beta \alpha \rho-\beta \alpha \rho$ con el perfecto latín dio origen... ¿a cuántas lenguas? Difícil contarlas; sólo en la península italiana, la más devastada por esas incursiones, se han formado catorce, no lenguas, sino grupos lingüísticos diferentes. Si buscamos noticias sobre los dialectos 
italianos en fuentes rápidas como las que se encuentran en internet, encontraremos afirmaciones insensatas como ésta: "Tras la caída del Imperio la inestabilidad política era muy grande y cada dialecto se arraigó a su región con mucha fuerza, generando así desunión entre sus regiones" (Ambitalia, "Dialectos italianos”). ¿Por qué se crearon tantas lenguas a partir del latín? ¿Ley del más fuerte? ¿Ley natural de evolución y decadencia de una lengua por verse obligada la población que la hablaba a absorber vocablos y conceptos nuevos?

La explicación real estriba en otro asunto, que pocos libros de historia, y menos la somera recopilación de datos de Wikipedia subrayan: al desmoronarse la fuerza de la Urbe, se vino abajo toda infraestructura social y política, y por lo tanto se vino abajo el sistema escolar. La falta de escuela significó la caída de la cultura latina, el difundirse del analfabetismo quitó todo freno al cambio progresivo de la lengua que diversificándose se multiplicó por esta cantidad difícilmente cuantificable de lenguas subalternas, de las cuales en nuestros tiempos hablamos oficialmente ésta de hoy y algunas más.

El griego se había sustraído a la ley del más fuerte, como lo adelantamos, gracias al prestigio y a la solidez de su cultura; y se había insertado en el sistema escolar romano volviéndose básico. El mismo Catón el Censor, que tanto había hostigado la difusión de la cultura griega que consideraba nefasta para las costumbres romanas, nos dice Cicerón en su De senectute que quiso aprender el griego a los noventa y dos años. Por lo que respecta el sánscrito, las más de tres mil reglas establecidas por Pānini fueron su baluarte hasta hoy.

La escuela es entonces el elemento clave para la supervivencia de las lenguas. ¿Cuál es entonces el papel que debe representar en la defensa de las lenguas hoy en día, en la época de la globalización, en la época de la escuela básica para todos, el instituto escolar, una Casa de Estudios?

Hagamos otro paso atrás en esta conversación, y volvamos a considerar el matiz peculiar, independiente y científico que han asumido la lingüística y la didáctica.

La gramática universal postulada por Chomsky, la función descriptiva de todos los estudios dirigidos a aclarar la esencia del fenómeno del lenguaje humano, a descubrir sus dinámicas internas, han hecho decaer la función normativa de las gramáticas, función básica e incontrovertible en los siglos (o milenios) transcurridos. Esta perspectiva se ha transmitido a la nueva pujante disciplina de la didáctica.

Las escuelas de todo el mundo han dejado decaer, inútil negarlo, la función normativa en la lengua materna. La enseñanza del latín se ha restringido (y al latín, no hay que olvidarlo, durante siglos se le llamaba "gramática"). El concepto de 'error' ha sido estigmatizado casi como el de la antigua 'corrección' con métodos digamos... manuales en la pedagogía infantil. Y la didáctica, esta nueva disciplina, que se ha centrado casi exclusivamente sobre el problema de la enseñanza de las lenguas extranjeras, no ha sido exenta de esta corriente.

Las metodologías didácticas se han sucedido con ritmo acelerado durante los últimos cincuenta años, presentándose todas, vez tras vez, con carácter definitivo. Se han concentrado como la lingüística, en la investigación de los mecanismos, por así decirlo, 


\section{$212 \square$ SIGNIFICADO DE UNA EDUCACIÓN MULTICULTURAL EN LA SOCIEDAD DE HOY}

biológicos del aprendizaje lingüístico. Las segundas lenguas se adquieren, y por eso son segundas lenguas, cuando el mecanismo todavía misterioso de la adquisición del primer lenguaje se ha apagado en el cerebro. Y por decenios el esfuerzo de la didáctica de los idiomas ha sido el de reproducir cuanto más de cerca la dinámica de este primer aprendizaje natural. (Por cierto, no sabemos con qué éxito Catón haya logrado aprender griego a sus noventa y dos años).

Esto, sin embargo, ha llevado a mecanizar el aprendizaje de otras lenguas, provocando a menudo el olvido de que apoderarse de una lengua extranjera significa acercarse a otra realidad, a otra experiencia vital de otro pueblo. Un acercamiento diferenciado que será indispensable también si el interés del aprendizaje lingüístico en el individuo responda a motivaciones esencialmente prácticas, de comunicación técnica o de trabajo.

El mito de la posible utilización de una lengua neutra universal, de una lengua franca, no perteneciente a ninguna cultura específica, no ha nacido solamente con el esperanto, a finales del siglo XIX. El latín, después de dejar de ser lengua hablada por un pueblo específico, mantenido en vida en ámbitos de estudio, fue lengua del pensamiento y de la ciencia durante siglos, y lengua de intercomunicación en altos niveles. A Galileo se le reprochó haber escrito en toscano el resultado de sus descubrimientos astronómicos, como un crimen lesae scientiae. Emmanuel Swedemborg escribió todavía en latín en el siglo XVIII su teología derivada de sus visiones (un latín por cierto, muy difícil de interpretar por su lejanía de los cánones clásicos). El esperanto fue una respuesta utópica a la desaparición del latín como lengua universal.

Encuentro esta hermosa definición de la finalidad de esta lengua facticia: "Su fin, era el de hacer dialogar los diferentes pueblos tratando de crear entre ellos comprensión y paz con una segunda lengua simple pero expresiva, perteneciente a la humanidad y no a un pueblo"* ("Lingua esperanto", Wikipedia). A esta finalidad ideal se añade la de "proteger" los idiomas "menores" que serían condenados a la extinción por la fuerza de idiomas y naciones más fuertes. Ludwik Lejzer, el polaco visionario Doktoro Esperanto, en 1872 tenía esa ilusión. Y su idioma 'universal' atrajo la esperanza, precisamente, de muchos idealistas anárquicos o revolucionarios en el siglo XX. El niño protagonista del primero de los deliciosos cuentos de Calvino agrupados bajo la definición facticia de "Amores difíciles", se llama Libereso, el nombre esperanto de la libertad: como el jardinero anárquico del padre de Calvino llamaba de hecho a su hijo.

No, el experimento del esperanto no sirvió, aunque esta lengua todavía se conozca y se use en ocasiones; aunque se hayan formado otras lenguas facticias, como la Lojban y la subsecuente Loglan, lenguas por cierto entendidas principalmente como transmisoras de datos matemático-técnicos.

No, las lenguas son vivas e independientes, y corresponden a la idiosincrasia de quien las habla, a su experiencia histórica, no pueden —no deben— reducirse a meca-

\footnotetext{
* Mi traducción.
} 
nismos amorfos. Que es el fenómeno que amenaza arrastrar también las lenguas así llamadas 'francas' aún siendo lenguas vivas, las que se hablan para intercomunicación (antes era el francés, ahora el inglés y también el español); lenguas que se desvirtúan al punto de obstaculizar en lugar de favorecer la comprensión.

La nueva corriente de didáctica de las lenguas ha adoptado el camino inverso, el del respeto de la correspondencia de cada lengua con la esencia de cada pueblo: y ha introducido, con elegancia griega, el término lenguacultura. No estamos hablando aquí de una metodología, sino de un enfoque. Del respeto a la identidad cultural de un idioma, del que derivarán metodologías apropiadas.

Es el momento, después de estas reflexiones que nos han llevado por varios derroteros, de sacar unas conclusiones.

1. La multiplicidad lingüística no es un castigo, sino una bendición que debemos saber apreciar y explotar en sus consecuencias. El acercamiento a otras culturas a través del aprendizaje lingüístico es y debe ser vehículo de tolerancia y aceptación, camino para el conocimiento de lo diverso y alternativo. Encuentro esta hermosa afirmación de Manuela Derosas, en el libro por ella compilado, Didáctica de las lenguasculturas: "en las sociedades en que vivimos el conocimiento de otros idiomas (y de otras culturas) se vuelve una de las herramientas indispensables a fin de una convivencia pacífica y de la construcción de sociedades democráticas, basadas en la participación activa de los ciudadanos o actores sociales" (290).

2. La enseñanza de las lenguas extranjeras es y debe ser prioritaria en el sistema escolar de un país moderno y avanzado; pero no se puede separar de la enseñanza de la cultura a la que la lengua que se enseña corresponde. El concepto de una lengua como simple instrumento de comunicación básica ha sido descartado. Y se ha constatado el fracaso de un concepto como el del esperanto, lengua 'neutra' sin características culturales propias. Una lengua corresponde a un país definido, que tiene su historia, sus producciones intelectuales y económicas específicas, su mentalidad; elementos todos que se reflejan en su lengua.

3. Un sistema escolar con buena función y unas reglas precisas - y lo hemos visto con el caso del latín, del griego y del sánscrito - son la base para la conservación de una lengua. Pero sobre todo lo que la mantiene viva es el interés cultural que se tenga en ella. Hay, en el mundo, y en este noble país, lenguas que requieren de atención escolarizada para mantenerse con su riqueza cultural. Estas lenguas 'menores' no deben, no pueden desaparecer.

(Como un ejemplo, en la región siciliana, en Italia, el 31 de mayo de 2011 se aprobó la Ley Número 9, en la que se hace obligatorio, en todas las escuelas de todos órdenes y grados, enseñar "el patrimonio lingüístico, histórico y literario" de Sicilia. Lo mismo esperan las lenguas originarias de México.) 


\section{$214 \square$ SIGNIFICADO DE UNA EDUCACIÓN MULTICULTURAL EN LA SOCIEDAD DE HOY}

4. Las universidades tienen hoy un cometido semejante al que tuvieron los conventos en los primeros siglos de la Edad Media, los siglos que llamamos oscuros: el de preservar la riqueza cultural en un mundo que ha soltado las bridas en la enseñanza, privilegiando lo funcional sobre lo intelectual, y aboliendo todo concepto de normatividad y preservación. La enseñanza de las lenguas-culturas ha de ser un punto focal. Pero no hay que equivocarnos. Las universidades tienen que mantener el rango de altos estudios para poder cumplir cabalmente con su función. Una universidad tiene que formar formadores; especialmente en nuestro ámbito de las humanidades. El estudio de las lenguas-culturas se debe perfeccionar, no iniciar, en el nivel universitario. El perfeccionamiento que se alcanza en nuestro ámbito $-\mathrm{y}$ la calidad de nuestro estudiantado es testimonio de lo que afirmo - ha de difundirse y reflejarse en los niveles preuniversitarios, los niveles en que el joven - libremente - escoge a cuál lengua-cultura apegarse por sus intereses o proyectos de vida. Las perspectivas intelectuales y prácticas que las lenguas eminentes ofrecen son múltiples. Los jóvenes deben tener acceso a estas posibilidades, es su derecho; pero deben acercarse a las lenguas extranjeras como al producto de una cultura diferente y enriquecedora, no sólo como a un conjunto de habilidades mecánicas, que a la postre no facilitarán la comprensión ni la comunicación. Las disciplinas que se imparten en este Colegio de Letras Modernas para preparar a futuros profesionales de las lenguas extranjeras, deben ser dirigidas hacia el alumnado de los niveles preuniversitarios.

Ésta es nuestra forma de pensar, éste es el programa que justifica la existencia de nuestro Colegio, que revalida los decenios de esfuerzos, la subida de nivel académico, la ampliación de perspectivas de todos los que nos han precedido, de los que están ahora dedicando su tiempo y capacidades, de los jóvenes que se están integrando. Y a esto hemos dedicado estas dos Jornadas de reflexión.

\section{Obras citadas}

Derosas, Manuela y Paolo Torresan, coords. 2011. Didáctica de las lenguasculturas. Nuevas perspectivas. Buenos Aires/Santiago/Montevideo/México/Florencia/Roma: SB-Alma.

“Dialectos italianos". Idioma. Ambitalia, 2007. 15 de agosto de 2012. < http://www. ambitalia.com.uy/idioma/dialectos-italianos.php>.

“Lingua esperanto". Wikipedia, la Enciclopedia Libre. 15 de agosto de 2012. $<$ https://it.wikipedia.org/wiki/Lingua_esperanto $>$.

Q. Horati Flacci. 1915. Epistolae Liber secundus, Opera. Florencia: Barbera.

“The New York Times Book Review". The New York Times. 25 de febrero de 1979. 